\title{
PRODUÇÃO DE MUDAS DE MAMOEIRO UTILIZANDO DIFERENTES SUBSTRATOS, AMBIENTES DE CULTIVO E RECIPIENTES
}

\author{
EDÍLSON COSTA ${ }^{1}$, LÉIA C. R. DOS SANTOS ${ }^{2}$, LAURA C. R. VIEIRA ${ }^{3}$
}

\begin{abstract}
RESUMO: No Estado de Mato Grosso do Sul, a fruticultura é limitada de informações consistentes, referentes ao potencial de produção de mudas para exploração a campo. Este trabalho avaliou a produção de biomassa em mudas de mamoeiro em diferentes ambientes de cultivo, recipientes e substratos na Universidade Estadual de Mato Grosso do Sul, Aquidauana - MS, de setembro a novembro de 2006. Utilizaram-se os ambientes de cultivo: estufa com filme de polietileno de baixa densidade; viveiro com tela de monofilamento preta; viveiro com tela aluminizada e viveiro com palha de coqueiro nativo. Os substratos "solo + composto orgânico + vermiculita", "solo + composto orgânico + pó de serra" e "solo + composto orgânico + vermiculita + pó de serra" preencheram as sacolas de polietileno e bandejas de poliestireno. O delineamento foi inteiramente casualizado em parcelas subsubdivididas. $\mathrm{O}$ ambiente com tela aluminizada promoveu os maiores acúmulos de biomassa do mamoeiro para as sacolas de polietileno. A sacola de polietileno foi o melhor recipiente para a produção de mudas do mamoeiro. Os substratos que continham vermiculita promoveram maiores acúmulos de biomassa nas sacolas de polietileno. $\mathrm{O}$ ambiente com tela aluminizada propiciou maior massa seca foliar nas três composições de substratos.
\end{abstract}

PALAVRAS-CHAVE: Carica papaya L., estufa, sacolas, bandejas.

\section{PRODUCTION OF PAPAYA SEEDLINGS USING DIFFERENTS SUBSTRATES, ENVIRONMENTS AND POTS}

\begin{abstract}
In the State of Mato Grosso do Sul, the cultivation of fruits is limited of consistent information, concerning the potential for production of seedlings for field production. This work evaluated papaya seedlings biomass production in different environments, pots, and substrates in the State University of Mato Grosso do Sul, Aquidauana - MS, Brazil, from September to November, 2006. The cultivation environments were: greenhouse with low density polyethylene film; nursery with monofilament black screened; nursery with aluminized screened and nursery with straw of native coconut palm. The substrates "soil + organic compost + vermiculite", "soil + organic compost + sawdust" and "soil + organic compost + vermiculite + sawdust" filled the polyethylene bags and polystyrene trays. The experiment consisted of a completely randomized statistical analysis in split-split-plot. The environment with aluminized screened promoted the greatest biomass accumulation for the polyethylene bags. The polyethylene bag was the best pots for papaya seedlings production. The substrates containing vermiculite promoted greater biomass in polyethylene bags. The environments with aluminized screened promoted greater leaf dry mass in the three substrates compositions.
\end{abstract}

KEYWORDS: Carica papaya L., greenhouse, bags, trays.

\footnotetext{
${ }^{1}$ Prof. Dr., Universidade Estadual de Mato Grosso do Sul, Unidade Universitária de Aquidauana, Rodovia Aquidauana - CERA, km 12, Zona Rural, Aquidauana - MS, Fone: (0XX67) 3904.2905, Fax: (0XX67) 3904.2907, mestrine@uems.br

${ }_{2}^{2}$ Mestranda, Programa de Pós-Graduação em Agronomia (Produção Vegetal), UEMS/Aquidauana, leiasantos_agro@yahoo.com.br

${ }^{3}$ Mestranda, Programa de Pós-Graduação em Agronomia (Produção Vegetal), UEMS/Aquidauana, laura26agro@ibest.com.br

Recebido pelo Conselho Editorial em: 17-3-2008

Aprovado pelo Conselho Editorial em: 9-10-2009
} 


\section{INTRODUÇÃO}

A produção de mudas em ambientes protegidos promove melhor crescimento e desenvolvimento da planta e, consequentemente, melhores produções a campo (CAVALCANTE et al., 2002). Para ZANELLA et al. (2006), a utilização de sombreamento é uma importante técnica na formação de mudas de fruteiras, pois afeta diretamente o crescimento da planta e posteriormente a formação do pomar.

No interior de ambientes protegidos cobertos com filme de polietileno, à medida que a temperatura do ar aumenta, em função do aumento da disponibilidade energética na superfície do solo (radiação solar global), a umidade relativa do ar diminui em função do aquecimento do ar (COSTA et al., 2004); dessa forma, ocorre a inibição do processo convectivo devido à barreira imposta pela presença do filme plástico no ambiente protegido (CUNHA \& ESCOBEDO, 2003), provocando o efeito estufa. Nesse processo, pode ocorrer maior evapotranspiração em função do gasto de energia e, consequentemente, acarretar menor desenvolvimento das plantas.

O déficit hídrico na planta e/ou no solo pode provocar diversos efeitos, que, de acordo com TAIZ \& ZEIGER (2004), podem levar às abscisões foliares, fechamento dos estômatos, limitação da fotossíntese, reduzindo a área foliar, o número de folhas e o crescimento das plantas. A redução na taxa fotossintética por unidade de área em plantas sob estresse hídrico é atribuída, especialmente, ao fechamento estomático.

VIEIRA et al. (2004) comentam que o cultivo protegido de mudas de mamoeiro pode ser uma boa alternativa no controle de viroses, como, por exemplo, o mosaico do mamoeiro, fator limitante ao desenvolvimento da planta em campo; dessa forma, o correto manejo dos ambientes protegidos devem ser promovidos visando à viabilização do seu uso.

Para MENDONÇA et al. (2003), as sacolas de polietileno para produção de mudas de mamoeiro proporcionam melhor vigor às plantas. ARAÚJO et al. (2006) observaram que os recipientes proporcionam alturas desuniformes às mudas do mamoeiro, sendo que as bandejas promovem o menor desenvolvimento, e as sacolas, nas dimensões de 20 x $32 \mathrm{~cm}$, mostraram-se como melhor acondicionamento.

MINAMI (2000) relata que o substrato é um componente de grande importância na produção vegetal e deve possuir todos os nutrientes necessários ao desenvolvimento das plantas. MENDONÇA et al. (2006) destacam que substratos adubados com $10 \mathrm{~kg} \mathrm{~m}^{-3}$ de superfosfato promovem mudas de mamoeiro de qualidade, substratos com $40 \%$ de composto orgânico mostraram - se eficientes e viáveis no fornecimento de matéria orgânica à planta. Para MENDONÇA et al. (2003), a utilização de substrato contendo "esterco de curral + carvão vegetal + solo + areia, na proporção de 2:1:1:1 v/v", e para NEGREIROS et al. (2005), os substratos à base de "esterco de curral + solo + areia + vermiculita, na proporção de 2:1:1:1 v/v", e "Plantmax® + esterco de curral + solo + areia, na proporção 1:1:1:1 v/v", apresentam condições favoráveis ao desenvolvimento de mudas de mamoeiro.

Este trabalho teve como objetivo avaliar diferentes ambientes, recipientes e substratos na formação de mudas de mamoeiro na região do alto pantanal sul-mato-grossense, estudando o acúmulo de biomassa aérea e radicular em plântulas, aos 50 dias após a semeadura.

\section{MATERIAL E MÉTODOS}

O experimento foi conduzido entre os meses de setembro e novembro de 2006, em área experimental da Universidade Estadual de Mato Grosso do Sul, em Aquidauana - MS, que se localiza à altitude de 174 m, longitude de $55^{\circ} 47^{\prime}$ e latitude de $20^{\circ} 28^{\prime}$.

Foram produzidas mudas de mamoeiro Carica papaya L., cultivar 'Sunrise Solo', mais conhecida como mamão Papaya, em quatro ambientes de cultivo, sendo A1 - estufa plástica, tipo capela, coberta com filme plástico de polietileno de baixa densidade, 150 mícrons de espessura, 
fechada lateral e frontalmente com tela de sombreamento de monofilamento, malha para $50 \%$ de sombra; A2 - viveiro telado, com fechamentos na cobertura, frontal e lateral com tela de sombreamento de monofilamento, malha para 50\% de sombra; A3 - viveiro telado, com fechamentos na cobertura, frontal e lateral com tela de sombreamento aluminizada (aluminet (®), malha para 50\% de sombra; A4 - viveiro coberto com palha de coqueiro nativo da região, conhecido popularmente como buriti, construído de madeira, nas dimensões de $3,0 \mathrm{~m}$ de comprimento por $1,20 \mathrm{~m}$ de largura e $1,70 \mathrm{~m}$ de altura, com bancadas a $0,80 \mathrm{~m}$ do solo, sem fechamentos lateral e frontal. Os ambientes protegidos A1, A2 e A3 foram construídos de madeira, possuindo dimensões de 5,0 $\mathrm{m}$ de comprimento por 5,0 $\mathrm{m}$ de largura e 2,50 $\mathrm{m}$ de pé-direito.

Foram utilizados dois tipos de recipientes: R1 - sacolas de polietileno, 15 x $25 \mathrm{~cm}$, e R2 bandejas de poliestireno, contendo 72 células, acomodados em bancadas de madeira de 3,0 m de comprimento por $1,20 \mathrm{~m}$ de largura e $0,80 \mathrm{~m}$ de altura. Os três substratos utilizados foram: $\mathrm{S} 1$ - solo + composto orgânico + vermiculita, na proporção volumétrica de 1:1:1 v/v); S2 - solo + composto orgânico + pó de serra, na proporção volumétrica de 1:1:1 v/v, e S3 - solo + composto orgânico + vermiculita + pó de serra, na proporção volumétrica de 1:1:1/2:1/2 v/v.

Utilizou-se do delineamento experimental em parcelas subsubdivididas ("split-split plot"), com 15 repetições. As parcelas principais foram os ambientes de cultivo (A), as subparcelas foram os recipientes $(\mathrm{R})$ e as subsubparcelas foram as composições de substratos $(\mathrm{S})$. O solo para preparo dos compostos foi obtido da área da Unidade Universitária de Aquidauana (UUA), na camada de 10 a $40 \mathrm{~cm}$, com composição química conforme Tabela 1. Utilizou-se do composto orgânico fabricado pela empresa Organoeste, denominado Organosuper® (Tabela 2).

TABELA 1. Atributos químicos do solo, na camada de 20 a $40 \mathrm{~cm}$, utilizado na composição dos substratos. Chemical attributes of soil in the layer of 20 to $40 \mathrm{~cm}$, used in the substrates composition.

\begin{tabular}{|c|c|c|c|c|c|c|c|}
\hline $\begin{array}{c}\mathrm{pH} \\
\mathrm{CaCl}_{2}(1: 2,5)\end{array}$ & $\begin{array}{c}\mathrm{P} \\
\left.\mathrm{mg} \mathrm{dm}^{-3}\right)\end{array}$ & $\mathrm{Al}^{3+}$ & $\mathrm{Ca}^{2+}$ & $\begin{array}{c}\mathrm{Mg}^{2+} \\
-\mathrm{cmol}_{\mathrm{c}} \mathrm{dm}^{-3}-\end{array}$ & & & $\mathrm{K}$ \\
\hline 5,3 & 7,1 & 0 & 1,9 & 1,1 & & & 0,41 \\
\hline S.B. & CTC & CTC Efet. & MO & Areia Total & Silte & Argila & $\mathrm{V}$ \\
\hline------ & $-\mathrm{cmol}_{\mathrm{c}} \mathrm{dm}$ & --------- & $(\%)$ & --------------- & $\mathrm{kg}^{-1}$ & ----- & $(\%)$ \\
\hline 3,41 & 6,3 & 3,4 & 14,1 & 726 & 144 & 130 & 54 \\
\hline
\end{tabular}

Fonte: Análises realizadas no laboratório de solos da Embrapa Agropecuária Oeste (CPAO).

$\mathrm{P}$ - fósforo; $\mathrm{Al}^{3+}$ - alumínio; $\mathrm{Ca}^{2+}$ - cálcio; $\mathrm{Mg}^{2+}$ - magnésio; $\mathrm{H}+\mathrm{Al}$ - acidez potencial; $\mathrm{K}$ - potássio; $\mathrm{SB}$ - soma de bases; CTC - capacidade de troca de cátions; CTC efetiva; MO - matéria orgânica; V - saturação por bases.

TABELA 2. Análise do composto orgânico Organosuper®, fabricado pela empresa Organoeste, utilizado na composição dos substratos para produção de mudas de mamoeiro. Analysis of organic compound Organosuper $₫$, manufactured by the company Organoeste, used in the substrates composition for the papaya seedlings.

\begin{tabular}{|c|c|c|c|c|c|c|c|}
\hline $\mathrm{pH}$ & $\mathrm{N}$ & $\mathrm{P}$ & $\mathrm{K}$ & $\mathrm{Ca}^{2+}$ & $\mathrm{Mg}^{2+}$ & $\mathrm{S}$ & $\mathrm{Zn}$ \\
\hline 8,40 & 6,72 & 4,27 & 0,42 & 2,75 & 0,45 & 0,86 & 0,02 \\
\hline $\mathrm{Cu}$ & $\mathrm{Mn}$ & $\mathrm{Fe}^{2+}$ & $\mathrm{Si}$ & $\mathrm{C}$ & $\mathrm{C} / \mathrm{N}$ & MO & U \\
\hline 0,003 & 0,04 & 1,39 & 0,27 & 25,53 & 3,80 & 45,96 & 37,50 \\
\hline
\end{tabular}

Fonte: Organoeste.

$\mathrm{N}$ - nitrogênio; $\mathrm{P}$ - fósforo; $\mathrm{K}$ - potássio; $\mathrm{Ca}^{2+}$ - cálcio; $\mathrm{Mg}^{2+}$ - magnésio; $\mathrm{S}$ - enxofre; $\mathrm{Zn}$ - zinco; $\mathrm{Cu}$ - cobre; Mn - Manganês; $\mathrm{Fe}^{2+}$ - ferro; $\mathrm{Si}$ - silício; $\mathrm{C}$ - carbono; $\mathrm{C} / \mathrm{N}$ - relação carbono e nitrogênio; $\mathrm{MO}$ - matéria orgânica; $\mathrm{U}$ - umidade. 
O pó de serra utilizado foi obtido de madeireira da região, com idade de estocagem de, aproximadamente, um ano, uma vez que apresenta grande disponibilidade em Aquidauana. Não foram realizadas análises de características químicas desse material.

Aplicaram-se doses de 2,5 kg de superfosfato simples $\left(\mathrm{P}_{2} \mathrm{O}_{5}\right), 0,3 \mathrm{~kg}$ de cloreto de potássio $(\mathrm{KCl})$ e $1,5 \mathrm{~kg}$ de calcário dolomítico "filler" (PRNT de $100 \%$ de pureza), por metro cúbico de substrato. Os substratos ficaram em repouso por 31 dias antes da realização da semeadura, dentro dos ambientes, para melhor mineralização da matéria orgânica presente no composto orgânico, sendo irrigados com rega manual duas vezes ao dia, de manhã e de tarde. Esse procedimento de irrigação também foi realizado durante o crescimento e o desenvolvimento das plantas.

A semeadura ocorreu no dia 15-9-2006, com emergência no dia 25-9-2006. Colocaram-se duas sementes por recipiente ou célula e no dia 16-10-2006, 31 dias após a semeadura (DAS), quando as plantas apresentaram aproximadamente $5 \mathrm{~cm}$ de altura ou duas folhas definitivas, foi realizado o desbaste, deixando apenas uma planta por recipiente ou célula.

As mudas foram avaliadas aos 50 dias após a semeadura (DAS), medindo-se as massas fresca e seca da parte aérea e das raízes. A massa fresca foi medida em balança analítica, marca Bioprecisa, modelo FA2104N, com precisão de quatro casas decimais $(0,0001 \mathrm{~g})$ e posteriormente levada à estufa com circulação de ar forçada, marca Hydrosan, para secagem à temperatura de $65^{\circ} \mathrm{C}$, por $72 \mathrm{~h}$.

Foram coletadas as temperaturas das 9 h, 12 h e 15 h, máximas e mínimas, diariamente, de cada ambiente de cultivo, utilizando termômetros digitais com precisão de $0,1{ }^{\circ} \mathrm{C}$. As temperaturas foram analisadas num delineamento inteiramente casualizado, com quatro tratamentos (ambientes de cultivo $\mathrm{A} 1, \mathrm{~A} 2, \mathrm{~A} 3$ e $\mathrm{A} 4)$ e 50 repetições (50 dias de cultivo). Os dados foram submetidos à análise de variância, e as médias, ao teste de Tukey, a 5\% de probabilidade, utilizando o "software" ESTAT (1994).

\section{RESULTADOS E DISCUSSÃO}

A avaliação dos ambientes de cultivo das mudas de mamão, dos recipientes e dos substratos, considerando as biomassas foliar e radicular, demonstrou que o melhor ambiente de cultivo de mudas foi o viveiro com tela aluminizada para a massa fresca foliar (MFF), massa seca foliar (MSF) e massa fresca do sistema radicular (MSR). Como as temperaturas foram similares nos ambientes de cultivo (Tabela 7), possivelmente o telado com aluminet ${ }^{\circledR}$ promoveu melhor espalhamento interno da radiação fotossinteticamente ativa, com melhor conversão de fotoassimilados por meio da fotossíntese e, consequentemente, mudas com maior biomassa aérea.

$\mathrm{Na}$ estufa plástica, foi necessária maior quantidade de água diária, pois há maior evapotranspiração provocada pelo efeito estufa do filme de polietileno, que diminui a perda de calor do ambiente devido às ondas longas, elevando a temperatura, diminuindo a umidade relativa do ar e exigindo maior gasto de energia das mudas (COSTA et al., 2009). Já para a massa seca radicular (MSR), os ambientes com tela na cor preta de monofilamento e o ambiente com tela aluminizada não diferiram entre si, mas proporcionaram índices mais elevados que os demais tratamentos (Tabela 3).

A sacola de polietileno apresentou maiores valores que a bandeja de poliestireno, concordando com os comentários de OLIVEIRA et al. (1993) e RIBEIRO et al. (2005) de que as sementes envolvidas por quantidade maior de substrato apresentam melhor germinação e desenvolvimento das plantas.

A sacola de polietileno foi o melhor recipiente para a produção de mudas. O maior volume propiciou maiores espaço e disponibilidade de nutrientes para o desenvolvimento da planta, resultando em sistema radicular mais denso e vigoroso, concordando com os resultados obtidos por ARAÚJO et al. (2006) e MENDONÇA et al. (2003). Os substratos S1 e S3 não diferiram entre si na 
produção de biomassa foliar, mas sendo superiores ao substrato S2; no entanto, para a biomassa radicular, o substrato $\mathrm{S} 1$ foi maior que o $\mathrm{S} 3$ e esse maior que o $\mathrm{S} 1$ (Tabela 3).

Os substratos que continham vermiculita em suas composições (S1 e S3) apresentaram maior acúmulo de biomassa nas mudas de mamão, concordando com MINAMI (1995) e NEGREIROS et al. (2005) em relação à utilização desse material, e o substrato que continha pó de serra apresentou a menor produção de biomassa. A vermiculita condiciona maior espaço poroso, com grande capacidade de aeração e melhor retenção de água, explicando o maior acúmulo de biomassa nas mudas. Em contrapartida, o pó de serra possui alto valor na relação carbono/nitrogênio $(\mathrm{C} / \mathrm{N})$, que imobiliza o nitrogênio (SAMPAIO et al., 2008) e demanda maior tempo de estabilização biológica do substrato (BOFF et al., 2005), consequentemente, apresentando plantas com menor acúmulo de biomassa.

TABELA 3. Massa fresca da parte aérea (MFF), massa seca da parte aérea (MSF), massa fresca do sistema radicular (MFR) e massa seca do sistema radicular (MSR) avaliadas aos 50 DAS, para diferentes ambientes de cultivo, substratos e recipientes. Fresh mass of the aerial portion (MFF), dry mass of the aerial portion (MSF), fresh mass of the root portion (MFR), and dry mass of root portion (MSR), evaluated in the 50 days after the sowing on the environments, substrates and pots.

\begin{tabular}{|c|c|c|c|c|}
\hline \multicolumn{5}{|c|}{ Ambientes de Cultivo } \\
\hline & MFF (g) & MSF (g) & MFR (g) & $\operatorname{MSR}(\mathrm{g})$ \\
\hline A1 & $2,94 \mathrm{C}$ & $0,39 \mathrm{C}$ & $1,61 \mathrm{C}$ & $0,15 \mathrm{~B}$ \\
\hline $\mathrm{A} 2$ & $4,17 \mathrm{~B}$ & $0,54 \mathrm{~B}$ & $2,12 \mathrm{~B}$ & $0,18 \mathrm{~A}$ \\
\hline A3 & $5,62 \mathrm{~A}$ & $0,66 \mathrm{~A}$ & $2,55 \mathrm{~A}$ & $0,17 \mathrm{~A}$ \\
\hline A4 & $3,14 \mathrm{C}$ & $0,42 \mathrm{C}$ & $1,00 \mathrm{D}$ & $0,08 \mathrm{C}$ \\
\hline C.V. $(\%)$ & 33,21 & 32,02 & 47,20 & 38,01 \\
\hline \multicolumn{5}{|c|}{ Recipientes } \\
\hline R1 & $7,44 \mathrm{~A}$ & $0,92 \mathrm{~A}$ & $3,13 \mathrm{~A}$ & $0,24 \mathrm{~A}$ \\
\hline $\mathrm{R} 2$ & $0,49 \mathrm{~B}$ & $0,08 \mathrm{~B}$ & $0,51 \mathrm{~B}$ & $0,05 \mathrm{~B}$ \\
\hline C.V. $(\%)$ & 34,22 & 32,94 & 49,32 & 39,57 \\
\hline \multicolumn{5}{|c|}{ Substratos } \\
\hline S1 & $5,03 \mathrm{~A}$ & $0,66 \mathrm{~A}$ & $2,56 \mathrm{~A}$ & $0,21 \mathrm{~A}$ \\
\hline S2 & $1,99 \mathrm{~B}$ & $0,23 \mathrm{~B}$ & $0,62 \mathrm{C}$ & $0,05 \mathrm{C}$ \\
\hline $\mathrm{S} 3$ & $4,89 \mathrm{~A}$ & $0,61 \mathrm{~A}$ & $2,28 \mathrm{~B}$ & $0,18 \mathrm{~B}$ \\
\hline C.V. $(\%)$ & 38,13 & 34,18 & 47,58 & 39,60 \\
\hline
\end{tabular}

* Médias seguidas de mesma letra, na coluna, não diferem entre si, pelo teste de Tukey, a 5\% de probabilidade. A - ambientes de cultivo; $\mathrm{R}$ - recipientes; $\mathrm{S}$ - substratos.

As interações entre ambientes e recipientes mostraram que o maior volume de substrato (R1) apresentou os maiores valores de biomassa, dentro de todos os ambientes analisados. Para o recipiente $\mathrm{R} 1$, o ambiente com tela aluminizada apresentou melhor desenvolvimento para os parâmetros de MFF, MSF e MFR, contudo, para a MSR, os ambientes telados A2 e A3 proporcionaram maiores valores que o ambiente A1 (Tabela 4).

Assim como explicitado anteriormente, o maior volume do recipiente permitiu maior crescimento do sistema radicular em função de maior disponibilidade de nutrientes, e o ambiente com tela termorrefletora (aluminet ${ }^{\circledR}$ ) pode ter promovido melhor disponibilidade de radiação fotossinteticamente ativa.

Os ambientes de cultivo telados (A2 e A3) promoveram melhor proteção à muda; por apresentar tela lateral, proporcionavam barreiras aos ventos, permitindo maiores acúmulos de biomassa em recipientes com maior volume (R1), conforme observado por MENDONÇA et al. (2003). 
TABELA 4. Valores de massa fresca da parte aérea (MFF), massa seca da parte aérea (MSF), massa fresca do sistema radicular (MFR) e massa seca do sistema radicular (MSR) para diferentes ambientes e substratos. Interactions between environments and pots to fresh mass of the aerial portion (MFF), dry mass of the aerial portion (MSF), fresh mass of the root portion (MFR) and dry mass of root portion (MSR).

\begin{tabular}{ccccc}
\hline \multicolumn{5}{c}{ Massa fresca da parte aérea $(\mathrm{g})$} \\
\hline \multicolumn{7}{c}{$\mathrm{A} 1$} & $\mathrm{~A} 2$ & $\mathrm{~A} 3$ & $\mathrm{~A} 4$ \\
$\mathrm{R} 1$ & $5,50 \mathrm{Ac}$ & $7,88 \mathrm{Ab}$ & $10,77 \mathrm{Aa}$ & $5,63 \mathrm{Ac}$ \\
$\mathrm{R} 2$ & $0,39 \mathrm{Ba}$ & $0,46 \mathrm{Ba}$ & $0,48 \mathrm{Ba}$ & $0,65 \mathrm{Ba}$ \\
\hline $\mathrm{r} 1$ & $0,77 \mathrm{Ac}$ & $1,01 \mathrm{Ab}$ & $1,23 \mathrm{Aa}$ & $0,68 \mathrm{Ac}$ \\
$\mathrm{R} 2$ & $0,07 \mathrm{Ba}$ & $0,08 \mathrm{Ba}$ & $0,09 \mathrm{Ba}$ & $0,10 \mathrm{Ba}$ \\
\hline \multicolumn{7}{c}{ Massa fresca do sistema radicular $(\mathrm{g})$} \\
\hline $\mathrm{R} 1$ & $2,67 \mathrm{Ac}$ & $3,71 \mathrm{Ab}$ & $4,57 \mathrm{Aa}$ & $1,57 \mathrm{Ad}$ \\
$\mathrm{R} 2$ & $0,55 \mathrm{Ba}$ & $0,54 \mathrm{Ba}$ & $0,53 \mathrm{Ba}$ & $0,43 \mathrm{Ba}$ \\
\hline $\mathrm{R} 1$ & $\mathrm{Ma}$ & $0,32 \mathrm{Aa}$ & $0,30 \mathrm{Aa}$ & $0,12 \mathrm{Ac}$ \\
$\mathrm{R} 2$ & $0,25 \mathrm{Ab}$ & $0,05 \mathrm{Ba}$ & $0,05 \mathrm{Ba}$ & $0,04 \mathrm{Ba}$ \\
\hline
\end{tabular}

* Médias seguidas de letras iguais maiúsculas nas colunas e minúsculas nas linhas não diferem entre si, pelo teste de Tukey, a 5\% de probabilidade. A - ambientes de cultivo; $\mathrm{R}$ - recipientes.

O recipiente (R2) não promoveu diferenças no acúmulo de biomassa, nos diferentes ambientes de cultivo, o qual, por possuir menor volume de substratos que as sacolas de polietileno e também em função das altas temperaturas, promoveu maior evapotranspiração, consequentemente, produzindo plantas menores, concordando com MENDONÇA et al. (2003) e LIMA et al. (2006). Para os ambientes A1 e A4, os substratos S1 e S3 apresentaram maiores valores que o substrato S2 para todas as variáveis, assim como no ambiente A2 para a MFR. Nos demais ambientes, o substrato S1 foi maior que o S3 e esse maior que o S2. Para o substrato S1, os ambientes telados (A2 e A3) promoveram maiores valores de biomassa que os demais ambientes.

Para os ambientes A1 e A4, os substratos S1 e S3 apresentaram maiores valores que o substrato S2 para todas variáveis, assim como no ambiente A2 para a MFR. Nos demais ambientes o substrato $\mathrm{S} 1$ foi maior que o S3, e esse maior que o S2. Para o substrato S1, os ambientes telados (A2 e A3) promoveram maiores valores de biomassa que os demais ambientes.

Para os substratos S2 e S3, o ambiente A3 apresentou maior valor de MSF, no entanto, para os parâmetros de biomassa radicular, no substrato S2, o ambiente A3 apresentou maior valor que o ambiente A4, e no substrato S3, o ambiente A4 apresentou os menores acúmulos de biomassa (Tabela 5).

A exposição das plantas aos efeitos do clima (A4), especialmente ventos, pode ter promovido maior perda de água, fazendo com que as plantas não conseguissem manter a pressão suficiente para o alongamento celular, promovendo menores acúmulos.

O substrato S2 apresentou os menores acúmulos de biomassas. Uma explicação para esse menor acúmulo do substrato que continha pó de serra (S2) pode ser o tempo em que o mesmo recebeu irrigação e ficou em repouso antes da semeadura (30 dias), pois o mesmo poderia necessitar de maior tempo para adquirir estabilidade biológica (BOFF et al., 2005) por demandar suprimento de nitrogênio nesse processo de estabilização, pois, conforme SCHELLER (2001), no material pó de serra, a atividade microbiana necessita de suprimentos extras de nutrientes para iniciar sua decomposição, influenciando e desequilibrando o desenvolvimento inicial da planta, como observado em experimento realizado com cebola. 
TABELA 5. Valores de massa seca da parte aérea (MSF), massa fresca do sistema radicular (MFR) e massa seca do sistema radicular (MSR) para diferentes ambientes e substratos. Interactions between environments and substrates to fresh mass of the aerial portion (MFF), fresh mass of the root portion (MFR) and dry mass of root portion (MSR).

\begin{tabular}{ccccc}
\hline \multicolumn{5}{c}{ Massa seca da parte aérea $(\mathrm{g})$} \\
\hline $\mathrm{S} 1$ & $\mathrm{~A} 1$ & $\mathrm{~A} 2$ & $\mathrm{~A} 3$ & $\mathrm{~A} 4$ \\
$\mathrm{~S} 2$ & $0,52 \mathrm{Ac}$ & $0,75 \mathrm{Ab}$ & $0,86 \mathrm{Aa}$ & $0,52 \mathrm{Ac}$ \\
$\mathrm{S} 3$ & $0,17 \mathrm{Bc}$ & $0,27 \mathrm{Cb}$ & $0,38 \mathrm{Ca}$ & $0,09 \mathrm{Bc}$ \\
\hline \multicolumn{7}{c}{$0,56 \mathrm{Ab}$} & $0,62 \mathrm{Bb}$ & $0,73 \mathrm{Ba}$ & $0,55 \mathrm{Ab}$ \\
\hline $\mathrm{S} 1$ & \multicolumn{4}{c}{ Massa fresca do sistema radicular $(\mathrm{g})$} \\
$\mathrm{S} 2$ & $0,58 \mathrm{Ac}$ & $3,00 \mathrm{Ab}$ & $4,01 \mathrm{Aa}$ & $1,35 \mathrm{Ac}$ \\
$\mathrm{S} 3$ & $2,37 \mathrm{Aa}$ & $0,75 \mathrm{Bb}$ & $0,91 \mathrm{Ca}$ & $0,25 \mathrm{Bb}$ \\
\hline \multicolumn{7}{c}{$\mathrm{Ma}$} & $2,61 \mathrm{Aa}$ & $2,74 \mathrm{Ba}$ & $1,40 \mathrm{Ab}$ \\
\hline $\mathrm{S} 1$ & $0,18 \mathrm{Ab}$ & $0,27 \mathrm{Aa}$ & $0,26 \mathrm{Aa}$ & $0,11 \mathrm{Ac}$ \\
$\mathrm{S} 2$ & $0,05 \mathrm{Bb}$ & $0,07 \mathrm{Ca}$ & $0,07 \mathrm{Ca}$ & $0,02 \mathrm{Bb}$ \\
\hline & $0,21 \mathrm{Aa}$ & $0,20 \mathrm{Ba}$ & $0,19 \mathrm{Ba}$ & $0,11 \mathrm{Ab}$ \\
\hline
\end{tabular}

* Médias seguidas de letras iguais maiúsculas nas colunas e minúsculas nas linhas não diferem entre si, pelo teste de Tukey, a 5\% de probabilidade. A - ambientes de cultivo; S - substratos.

Observa-se que os substratos S1 e S3 proporcionaram maiores valores que o substrato S2, com exceção para a MFF no recipiente R2, em que os três substratos não diferiram. Provavelmente, o volume das células (R2), por apresentar menor quantidades de nutrientes e água, para os três substratos, não interferiu nos valores de massa fresca foliar. Para todos os substratos, o recipiente com maior capacidade de substrato (R1) apresentou os maiores valores de biomassa (Tabela 6).

A maior percentagem de vermiculita no substrato (S1) do recipiente com maior volume (R1) promoveu plantas com maiores massas secas aéreas e radiculares, resultado explicado pelas propriedades desse material com grande capacidade de aeração e de retenção de água.

TABELA 6. Valores de massa fresca da parte aérea (MFF), massa seca da parte aérea (MSF), massa fresca do sistema radicular (MFR) e massa seca do sistema radicular (MSR) para diferentes recipientes e substratos. Interactions between pots and substrates to fresh mass of the aerial portion (MFF), dry mass of the aerial portion (MSF), fresh mass of the root portion (MFR) and dry mass of root portion (MSR).

\begin{tabular}{cccc}
\hline \multicolumn{5}{c}{$\mathrm{S} 1$} & $\mathrm{~S} 2$ & $\mathrm{~S} 3$ \\
\hline $\mathrm{R} 1$ & \multicolumn{1}{c}{ Massa fresca da parte aérea $(\mathrm{g})$} \\
$\mathrm{R} 2$ & $9,40 \mathrm{Aa}$ & $3,80 \mathrm{Ab}$ & $9,12 \mathrm{Aa}$ \\
\hline \multicolumn{5}{c}{$0,66 \mathrm{Ba}$} & $0,17 \mathrm{Ba}$ & $0,65 \mathrm{Ba}$ \\
\hline $\mathrm{R} 1$ & Massa seca da parte aérea $(\mathrm{g})$ \\
$\mathrm{R} 2$ & $1,21 \mathrm{Aa}$ & $0,43 \mathrm{Ac}$ & $1,12 \mathrm{Ab}$ \\
\hline $\mathrm{R} 1$ & $0,11 \mathrm{Ba}$ & $0,03 \mathrm{Bb}$ & $0,11 \mathrm{Ba}$ \\
\hline $\mathrm{R} 2$ & Massa fresca do sistema radicular $(\mathrm{g})$ \\
\hline $\mathrm{R} 1$ & $4,41 \mathrm{Aa}$ & $1,06 \mathrm{Ac}$ & $3,92 \mathrm{Ab}$ \\
$\mathrm{R} 2$ & $0,71 \mathrm{Ba}$ & $0,19 \mathrm{Bb}$ & $0,65 \mathrm{Ba}$ \\
\hline
\end{tabular}

* Médias seguidas de letras iguais maiúsculas nas colunas e minúsculas nas linhas não diferem entre si, pelo teste de Tukey, a 5\% de probabilidade. $\mathrm{R}$ - recipientes; $\mathrm{S}$ - substratos. 
O volume do recipiente influenciou no acúmulo de biomassa radicular e na aérea do mamoeiro, efeito nítido apresentado pelas massas secas desses parâmetros em todos os substratos, evidenciando que recipientes pequenos limitam o crescimento da planta, produzindo mudas de baixa qualidade, concordando com LIMA et al. (2006), que trabalharam com a produção de mudas de mamoneira em diferentes volumes de recipientes.

Os ambientes A2 e A3, mesmo não diferindo estatisticamente dos ambientes A1 e A4 em relação às temperaturas coletadas, foram os que apresentaram os melhores desenvolvimentos às mudas (Tabela 7). Esses ambientes, por apresentar tela lateral, proporcionavam barreiras aos ventos fortes. Verificou-se que a temperatura máxima no ambiente $\mathrm{A} 1$ foi de $1,4{ }^{\circ} \mathrm{C}$ acima da temperatura máxima no ambiente $\mathrm{A} 3$, caracterizando o maior efeito da cobertura plástica sobre as temperaturas máximas, conforme relatado por SCATOLINI (1996).

TABELA 7. Temperatura média do ar $\left({ }^{\circ} \mathrm{C}\right)$ às $9 \mathrm{~h}, 12 \mathrm{~h}$ e $15 \mathrm{~h}$, temperatura média máxima (Tmáx.) e temperatura média mínima (Tmín.) para cada ambiente de cultivo. Average air temperature $\left({ }^{\circ} \mathrm{C}\right)$ at $9 \mathrm{~h}, 12 \mathrm{~h}$ and $15 \mathrm{~h}$ and maximum and minimum from September 15 to December 13 for each environment (A).

\begin{tabular}{cccccc}
\hline & $9 \mathrm{~h}$ & $12 \mathrm{~h}$ & $15 \mathrm{~h}$ & Tmáx. & Tmín. \\
\hline A1 & $29,5 \mathrm{a}$ & $33,1 \mathrm{a}$ & $32,3 \mathrm{a}$ & $37,1 \mathrm{a}$ & $21,3 \mathrm{a}$ \\
A2 & $29,2 \mathrm{a}$ & $32,5 \mathrm{a}$ & $31,5 \mathrm{a}$ & $35,8 \mathrm{a}$ & $21,5 \mathrm{a}$ \\
A3 & $29,2 \mathrm{a}$ & $32,4 \mathrm{a}$ & $32,0 \mathrm{a}$ & $35,7 \mathrm{a}$ & $21,0 \mathrm{a}$ \\
A4 & $29,8 \mathrm{a}$ & $33,2 \mathrm{a}$ & $32,2 \mathrm{a}$ & $36,8 \mathrm{a}$ & $21,7 \mathrm{a}$ \\
C.V. $(\%)$ & 10,4 & 11,5 & 15,9 & 10,3 & 12,0 \\
\hline
\end{tabular}

* Médias seguidas de mesma letra na coluna não diferem entre si, pelo teste de Tukey, a 5\% de probabilidade.

A - ambientes de cultivo.

As altas temperaturas provocam baixas umidades relativas, e essa relação inversa entre temperatura e umidade relativa provoca maior evapotranspiração na cultura, sendo um efeito desejado, porém necessita de alto controle das irrigações para evitar o estresse hídrico (A1). Como as irrigações foram realizadas apenas nos períodos da manhã e da tarde, as plantas ficaram todo o período de maior estresse térmico em alto processo de evaporação e transpiração, resultando em plantas com menor acúmulo de biomassa no ambiente A1 que, sendo coberto com filme de polietileno, provocou o efeito estufa (CUNHA \& ESCOBEDO, 2003).

No ambiente A2, coberto com tela de monofilamento na cor preta, malha para $50 \%$ de sombra, observou-se a necessidade de controlar a quantidade de água na irrigação devido à presença de fungos em todos os recipientes, provocado pelo sombreamento que reduziu a passagem de luz e propiciou a proliferação desses patógenos, e por ser um ambiente que permitiu a entrada de água pluvial, que no período do experimento foi de $208 \mathrm{~mm}$. Esse efeito promoveu menor evaporação no ambiente, além da redução da transpiração da planta, permitindo condições mais propícias para o desenvolvimento, concordando com resultados obtidos por ARAÚJO et al. (2006) e BURIOL et al. (1994).

A elevada radiação solar é o principal fator que limita o rendimento das espécies em campo e em ambientes protegidos. A redução da radiação solar no interior de ambientes protegidos varia de 5 a 35\% em relação ao meio externo (PURQUERIO \& TIVELLI, 2006). No ambiente A3, devido à maior reflexão dos raios solares promovida por esse tipo de tela (GUISELINI \& SENTELHAS, 2004) permitiu menor radiação interna no ambiente, promovendo melhor desenvolvimento às mudas que os ambientes A1 e A4. Esses valores de redução da radiação interna variam com o percentual de sombreamento, com o ângulo de elevação do sol (estação do ano e hora do dia) e também dependem da reflexão e da absorção pelo material.

O ambiente A4, coberto com palha de coqueiro, obteve resultados inferiores aos ambientes de cultivo telados, explicado pela exposição das plantas aos efeitos do clima, principalmente aos ventos, que podem ter promovido maiores perdas de água, fazendo com que as plantas não 
conseguissem manter a pressão suficiente para o alongamento celular, promovendo plantas menores (TAIZ \& ZEIGER, 2004).

\section{CONCLUSÕES}

O ambiente com tela aluminizada promoveu os maiores acúmulos de biomassa do mamoeiro para as sacolas de polietileno, excetuando a massa seca do sistema radicular, onde esse ambiente promoveu acúmulo similar ao ambiente com tela de monofilamento.

Independentemente do tipo de substrato e do tipo de ambiente de cultivo, a sacola de polietileno foi o melhor recipiente para a produção de mudas do mamoeiro.

Os substratos que continham vermiculita apresentaram melhores resultados, independentemente do tipo de ambiente de cultivo, promovendo maiores acúmulos de biomassa nas sacolas de polietileno.

O ambiente com tela aluminizada propiciou maior matéria seca foliar nas três composições de substratos e maior massa fresca do sistema radicular nos substratos S1 e S2, sendo similar ao ambiente com tela de monofilamento para a massa seca do sistema radicular nesses dois substratos.

\section{AGRADECIMENTOS}

À Pró-Reitoria de Pesquisa e Pós-Graduação (PROPP) da Universidade Estadual de Mato Grosso do Sul (UEMS), pelos recursos de auxílio à pesquisa, concedidos aos projetos de Iniciação Científica, tornando possível a realização deste trabalho.

\section{REFERÊNCIAS}

ARAÚJO, J.G.; ARAÚJO JÚNIOR, M.M.; MENEZES, R.H.N.; MARTINS, M.R.; LEMOS, R.N.S.; CERQUEIRA, M.C. Efeito do recipiente e ambiente de cultivo sobre o desenvolvimento de mudas de mamoeiro cv. sunrise solo. Revista Brasileira de Fruticultura, Jaboticabal, v.28, n.3, p.526-529, 2006.

BOFF, P.; DEBARBA, J.F.; SILVA, E.; WERNER, H. Qualidade e sanidade de mudas de cebola em função da adição de composto termófilo. Horticultura Brasileira, Brasília, v.23, n.4, p.875-880, 2005.

BURIOL, G.A.; STRECK, N.A.; GIMENES, E.S.; SCHNEIDER, F.M. Alterações micrometeorológicas causadas por túneis baixos de tela plástica preta cultivados com alface. Ciência Rural, Santa Maria, v.24, n.1, p 1-6, 1994.

CAVALCANTE, L.F.; SANTOS, J.B.; SANTOS, C.J.O.; FEITOSA FILHO, J.C.; LIMA, E.M.; CAVALCANTE, I.H.L. Germinação de sementes e crescimento inicial de maracujazeiros irrigados com água salina em diferentes volumes de substrato. Revista Brasileira de Fruticultura, Jaboticabal, v.24, n.3, p.748-751, 2002.

COSTA, E.; LEAL, P.M.; CARMO JÚNIOR, R.R. Modelo de simulação da temperatura e umidade relativa do ar no interior da estufa plástica. Engenharia Agrícola, Jaboticabal, v.24, n.1, p.57-67, 2004.

COSTA E.; RODRIGUES E.T.; ALVES, V.B.; SANTOS, L.C.R.; VIEIRA, L.C.R. Efeitos da ambiência, recipientes e substratos no desenvolvimento de mudas de maracujazeiro-amarelo em Aquidauana - MS. Revista Brasileira de Fruticultura, Jaboticabal, v.31, n.1, p.236-244, 2009.

CUNHA, A.R.; ESCOBEDO, J.F. Alterações micrometeorológicas causadas pela estufa plástica e seus efeitos no crescimento e produção da cultura de pimentão. Revista Brasileira de Agrometeorologia, Santa Maria, v.11, n.1, p.15-27, 2003.

ESTAT. Sistema para Análises Estatísticas (v.2.0). Jaboticabal: Departamento de Ciências Exatas, Faculdade de Ciências Agrárias e Veterinárias, Universidade Estadual Paulista, 1994. 
GUISELINI, C.; SENTELHAS, P.C. Uso de malhas de sombreamento em ambientes protegidos. I Efeito na temperatura e na umidade relativa do ar. Revista Brasileira de Agrometeorologia, Santa Maria, v.12, n.1, p.9-17, 2004.

LIMA, R.L.S.; SOARES, L.S.; SILVA, M.I.L.; VALE, L.S.; BELTRÃO, N.E.M. Volume de recipientes e composição de substratos para produção de mudas de mamoneira. Ciência e Agrotecnologia, Lavras, v.30, n.3, p.480-486, 2006.

MENDONÇA, V.; ARAÚJO NETO, S.E.; RAMOS, J.D.; PIO, R.; GONTIJO, T.C.A. Diferentes substratos e recipientes na formação de mudas de mamoeiro 'sunrise solo'. Revista Brasileira de Fruticultura, Jaboticabal, v.25, n.1, p.127-130, 2003.

MENDONÇA, V.; ABREU, N.A.A.; GURGEL, R.L.S.; FERREIRA, E.A.; ORBES, M.Y.; TOSTA, M.S. Crescimento de mudas de mamoeiro "formosa" em substratos com a utilização de composto orgânico e superfosfato simples. Ciência e Agrotecnologia, Lavras, v.30, n.5, p.861-868, 2006.

MINAMI, K. Produção de mudas em recipientes. In: . Produção de mudas de alta qualidade em horticultura. São Paulo: Fundação Salim Farah Maluf, 1995. cap. 3, p. 85-101.

MINAMI, K. A pesquisa em substrato no Brasil. In: KÄMPF, A.N.; FERMINO, M.H. Substratos para plantas: a base da produção vegetal em recipientes. Gênesis: Porto Alegre, 2000. p.159-162.

NEGREIROS, J.R.S.; BRAGA, L.R.; ÁLVARES, V.S.; BRUCKNER, C.H. Diferentes substratos na formação de mudas de mamoeiro do grupo solo. Revista Brasileira de Agrociência, Pelotas, v.11, n.1, p.101-103, 2005.

OLIVEIRA, R.P.; SCIVITTARO, W.B.; VASCONCELLOS, L.A.B.C. Avaliação de mudas de maracujazeiro em função do substrato e do tipo de bandeja. Scientia Agrícola, Piracicaba, v.50, n.2, p.261-266, 1993.

PURQUERIO, L.F.V.; TIVELLI, S.W. Manejo do ambiente em cultivo protegido. Manual técnico de orientação: projeto hortalimento. São Paulo: Codeagro, 2006. p. 15-29. Disponível em: http://www.iac.sp.gov.br. Acesso em: 15 mar. 2007.

RIBEIRO, M.C.C.; MORAIS, M.J.A. de; SOUSA, A.H.; LINHARES, P.C.F.; BARROS JÚNIOR, A.P. Produção de mudas de maracujá-amarelo com diferentes substratos e recipientes. Mossoró: Caatinga, Mossoró, v.18, n.3, p.155-158, 2005.

SAMPAIO, R.A.; RAMOS, S.J.; GUILHERME, D.O.; COSTA, C.A.; FERNANDES, L.A. Produção de mudas de tomateiro em substratos contendo fibra de coco e pó de rocha. Horticultura Brasileira, Brasília, v.26, n.4, p.499-503, 2008.

SCATOLINI, M.E. Estimativa da evapotranspiração da cultura de crisântemo em estufa a partir de elementos meteorológicos. 1996. 71 f. Dissertação (Mestrado em Irrigação e Drenagem) - Escola Superior de Agricultura “Luiz de Queiroz”, Universidade de São Paulo, Piracicaba, 1996.

SCHELLER, E. Fundamentos científicos da nutrição vegetal na agricultura ecológica. Tradução de B.T. Sixel. Botucatu: ABD, 2001. 78 p.

TAIZ, L.; ZEIGER, E. Fisiologia vegetal. 3. ed. Porto Alegre: Artmed, 2004. 719 p.

VIEIRA, M.R.; CORREA, L.S.; CASTRO, T.M.G.; SILVA, L.F.S.; MONTEVERDE, M.S. Efeito do cultivo do mamoeiro (Carica papaya L.) em ambiente protegido sobre a ocorrência de ácaros fitófagos e moscas-brancas. Revista Brasileira de Fruticultura, Jaboticabal, v.26, n.3, p.441-445, 2004.

ZANELLA, F.; SONCELA, R.; LIMA, A.L.S. Formação de mudas de "maracujazeiro-amarelo" som níveis de sombreamento em Ji-Paraná - RO. Ciência e Agrotecnologia, Lavras, v.30, n.5, p.880-884, 2006. 